\title{
Planejamento Estratégico Tributário: Um Estudo de Caso em Empresa do Ramo Varejista
}

\author{
Ubaldo de Jesus Fonsecal $^{1}$; João Sotero do Vale Júnior ${ }^{2}$; Carlos Magno Diniz Guerra de Andrade ${ }^{3}$
}

\begin{abstract}
Resumo: O presente artigo tem como objetivo de avaliar a importância do planejamento estratégico tributário como ferramenta de gestão eficaz, tomando como base uma empresa comercial do ramo varejista no recôncavo da Bahia. Porque tal ferramenta de gestão é importante para todas as empresas, independente do seu ramo de atividade ou porte econômico. O aporte teórico foi sustentado por: Catelli (1999), Gubert (2004), Maximiano (2006), Camasmie (2011), Lincoln (2011), Oliveira; Chieregato; Júnior e Gomes (2011) dentre outros. A pesquisa foi desenvolvida de forma exploratória e explicativa, para análise e tratamento dos dados foi utilizado o método quantitativo. Os resultados encontrados nesse estudo revelam que para realizar o planejamento estratégico tributário, faz-se necessário a consulta a especialistas (Contadores, Administradores ou Advogados) que estudem e/ou trabalhem nas áreas de finanças e tributos, a fim de orientar a alta administração na projeção futura e preventiva para tomada de decisões de forma segura.
\end{abstract}

Palavras-Chave: Gestão tributária; Planejamento estratégico; Planejamento tributário.

\section{Strategic Planning Tax: A Case Study In The Retailer Company}

\begin{abstract}
The objective of this article is to evaluate the importance of strategic tax planning as an effective management tool, based on a retail business in the Bahia state. Because such a management tool is important for all companies, regardless of their field of activity or economic size. The theoretical contribution was supported by: Catelli (1999), Gubert (2004), Maximiano (2006), Camasmie (2011), Lincoln (2011), Oliveira; Chieregato; Júnior e Gomes (2011) among others. The research was developed in an exploratory and explanatory way, for the analysis and treatment of the data the quantitative method was used. The results found in this study reveal that in order to carry out strategic tax planning, it is necessary to consult specialists (Accountants, Administrators or Lawyers) who study and / or work in the areas of finance and taxes, in order to guide senior management in future and preventive projection for decision making in a safe way.
\end{abstract}

Keywords: Tax management; Strategic planning; Tax planning.

\section{Introdução}

O fenômeno da globalização impactou de forma direta e sistêmica a política, a economia, e o comercio em todo o mundo, e no Brasil não foi diferente, pois, no cenário

\footnotetext{
${ }^{1}$ Administrador. Especialista em Docência no Ensino Superior pelo Centro Universitário Barão de Mauá - CUBM, Ribeirão Preto, São Paulo, Brasil. Especialista em Gestão Estratégica e Negócios pela Universidade do Estado da Bahia - UNEB, ubaldog12@yahoo.com.br, Santo Antônio de Jesus, Bahia, Brasil.

2 Administrador. Mestre em Administração pela Universidade Salvador - UNIFACS. Docente da disciplina de Gestão de Atacado e Varejo do Programa de Pós-Graduação em Gestão Estratégica e Negócios no da Universidade do Estado da Bahia - UNEB, joao.sotero.js@gmail.com, Santo Antônio de Jesus, Bahia, Brasil.

3 Administrador. Mestre em Administração pela Universidade Federal da Bahia - UFBA. Docente e coordenador da Programa de PósGraduação em Gestão Estratégica e Negócios da Universidade do Estado da Bahia - UNEB, cguerra@uneb.br, Santo Antônio de Jesus,
} Bahia, Brasil. 
mundial, o mesmo é visto como um país muito custoso para as empresas de quaisquer ramos econômicos. Isso, de fato, é devido à carga tributária brasileira que ocupa o $1^{\circ}$ (primeiro) lugar em toda a América Latina e Caribe, com o equivalente a 33,4\% do tamanho da economia em taxas e impostos. E sobre o consumo a carga tributária ainda é pior, pois os impostos equivalem a $70 \%$ da arrecadação, segundo a $\mathrm{OCDE}^{4}$.

Em relação ao mundo, a carga tributária brasileira ocupa a $14^{\circ}$ (décima quarta) posição, com $34,5 \%$ segundo o IBPT $^{5}$. Por conta de toda essa excessiva carga tributária (cobrança de $\operatorname{taxas}^{6}$ e impostos ${ }^{7}$ ), além de uma crise de confiança dos investidores, que propiciou uma queda de investimentos no país e uma instabilidade política, o Brasil vem sofrendo crises financeiras/econômicas, também chamadas de recessão ${ }^{8}$ e retração ${ }^{9}$, que tem provocado o fechamento em massa de várias empresas de diversos ramos comerciais.

De acordo com dados do IBGE $^{10}$ (2014), a crise econômica que assola o Brasil fez com que o número de empresas que saíram do mercado fosse maior do que as empresas que entraram no mercado, ou seja, em 2014 surgiram 726,3 mil novas empresas, enquanto 944 mil foram extintas. Os dados do $\operatorname{SEBRAE}^{11}$ (2014), informam que a taxa de mortalidade das empresas com até 2 (dois) anos de vida por porte chega em média a até $54 \%$ das $\mathrm{ME}^{\prime} \mathrm{S}^{12}$, entre (2008 e 2012), e por setor de segmento chega em média a até 49\% da construção civil e a até $48 \%$ dos serviços, entre (2008 e 2012).

A análise desses dados mostra como a economia tornou-se mais célere e seletiva, obrigando as empresas a se adaptarem para continuarem vivas e produtivas. Assim, as mesmas passaram a adotar o Planejamento Estratégico Tributário como forma de diminuição de seus custos tributários, de forma lícita e justa, para aumentar seu crescimento e lucro.

\footnotetext{
${ }^{4}$ OCDE - Organização para a Cooperação e Desenvolvimento Econômico.

${ }^{5}$ IBPT - Instituto Brasileiro de Planejamento Tributário.

${ }^{6}$ TAXAS - É o tributo contraprestacional de serviços públicos ou de benefícios feitos, postos à disposição ou custeados pelo Estado.

${ }^{7}$ IMPOSTOS - "É o tributo cuja obrigação tem por fato gerador uma situação independente de qualquer atividade estatal específica, relativa ao contribuinte".

${ }^{8}$ diminuição da atividade econômica, com queda da produção, desemprego.

9 diminuição do ritmo de crescimento da economia, ou seja, houve queda do consumo e consequentemente houve queda nas vendas e na produção das mercadorias.

${ }^{10}$ IBGE - Instituto Brasileiro de Geografia e Estatística.

${ }^{11}$ SEBRAE - Serviço Brasileiro de Apoio às Micro e Pequenas Empresas.

${ }^{12}$ ME'S - Microempresas.
} 
Desta forma, o objetivo geral da pesquisa consiste em avaliar a importância do planejamento estratégico tributário como ferramenta de gestão eficaz, tomando como exemplo uma empresa comercial do ramo varejista no recôncavo da Bahia.

\section{Gestão Tributária}

Antes mesmo de se falar em planejamento estratégico ou planejamento estratégico tributário, é de extrema importância conhecer e saber o que é a Gestão Tributária. Conforme Oliveira; Chieregato; Júnior e Gomes (2011, p. 16), pode-se entender Gestão Tributária como:

\footnotetext{
Especialização administrativa que tem como principais objetivos o estudo da teoria e a aplicação prática dos princípios e normas básicas da legislação tributária.

Ramo da administração responsável pelo gerenciamento dos tributos incidentes nas diversas atividades de uma empresa, ou grupo de empresas, adaptando ao dia a dia empresarial as obrigações tributárias, de forma a não expor a entidade às possíveis sanções fiscais e legais ou apurar o valor justo do tributo.
}

Ou seja, nos dias atuais para se fazer planejamento tributário é de extrema importância a contratação de profissionais que conheçam e entendam sobre o Sistema Tributário brasileiro, que é um dos mais complexos do mundo moderno, e esses profissionais devem ser contadores, contudo, deverão ser responsáveis: pela escrituração fiscal das atividades do dia a dia, apuração dos tributos a recolher, controle sobre os prazos de atendimento e recolhimento, assessoria para a correta apuração e registro do lucro tributável, assessoria para o correto registro contábil das provisões tributárias, orientação, treinamento, supervisão dos funcionários do setor de tributos e de impostos, além de estudar todas as alternativas legais para redução da carga fiscal/tributária (OLIVEIRA; CHIEREGATO; JÚNIOR E GOMES, 2011, p. 17).

\section{O que é Planejamento Estratégico Tributário?}

Deve-se ir por parte para se entender o que é planejamento estratégico tributário. Assim, primeiro é preciso entender o conceito de planejamento estratégico que, para Maximiano (2006), é o processo [...] que compreende a tomada de decisões sobre qual o 
padrão de comportamento que a organização pretende seguir [...]. Já o planejamento tributário é conceituado por Oliveira (1998, p. 24) como "uma maneira lícita de reduzir a carga fiscal". Para Gubert (2004), planejamento tributário “[...] é um conjunto de condutas, comissivas ou omissivas, da pessoa física ou jurídica, realizadas antes ou depois da ocorrência do fato gerador, destinadas a reduzir, mitigar, transferir ou postergar legal e licitamente os ônus dos tributos". Então, ao fazer-se a junção dessas terminologias: "planejamento estratégico tributário", estamos dando uma amplitude maximizada para a tomada de decisões dentro das empresas com foco principal na redução da carga fiscal/tributária, de maneira legal.

\title{
Papel do contador e da contabilidade no planejamento estratégico tributário
}

Segundo, Oliveira; Chieregato; Júnior e Gomes (2011, p. 17):

\begin{abstract}
O moderno e competente profissional da contabilidade já não pode limitar-se aos aspectos legais e fiscais da entidade. A essas importantes funções e atividades acrescentam-se outros aspectos importantes, tais como gerenciais, de produtividade, de eficiência e estratégicos.

A contabilidade pode ser de grande utilidade como um órgão de apoio administrativo, quando atua em consonância como os objetivos estratégicos da empresa [...].
\end{abstract}

Nesse novo senário de busca por lucratividade e economia tributária os antigos contadores (contadores tradicionais) que simplesmente escrituram documentos e calculam impostos, precisarão se reciclar, para poderem atender as empresas com eficiência ou perderão espaço, nesse novo e dinâmico contexto empresarial.

\section{Importância do Planejamento Estratégico Tributário}

A lei das sociedades por ações $6.404 / 76$, em seu artigo 153, afirma que "O administrador da companhia deve empregar, no exercício de suas funções, o cuidado e diligência que todo homem ativo e probo costuma empregar na administração dos seus próprios negócios". Então por interpretação evidencia-se que todos aqueles que são 
responsáveis diretos ou indiretos pelas entidades empresarias são obrigados a fazer o seu planejamento tributário, daí observa-se o tamanho da importância de tal fato para o ente empresarial de natureza jurídica. Vale ressaltar que um bom planejamento estratégico tributário (feito de forma lícita), causa uma diminuição legal no valor monetário (dinheiro), a ser repassado para o governo.

\title{
Objetivos a serem alcançados pelo planejamento estratégico tributário
}

O mesmo de forma direta e eficaz serve para evitar a incidência do tributo, nesse caso adota-se procedimentos com o fim de evitar a ocorrência do fato gerador; reduzir o montante do tributo, as providências serão no sentido de reduzir a base de cálculo ou alíquota do tributo; retardar o pagamento do tributo, o contribuinte adota medidas que têm por fim postergar o pagamento do tributo, sem ocorrência da multa. Oliveira; Chieregato; Júnior e Gomes (2011, p. 19), afirmam que "é necessário a simplificação das rotinas tributarias, porém enquanto isso não acontece as empresas precisam cada vez mais de planejamento tributário criterioso e criativo que possa resguardar os direitos do contribuinte e, ao mesmo tempo, proteger o patrimônio da entidade".

\section{Estrutura ideal para o Planejamento Estratégico Tributário}

Para Oliveira; Chieregato; Júnior e Gomes (2011, p. 20):

\begin{abstract}
Qualquer que seja a forma de tributação escolhida pela empresa, pode-se verificar que a falta de planejamento estratégico tributário pode deixar a empresa mal preparada para os investimentos, devido a uma possível insuficiência de caixa, gerando um desgaste desnecessário de investimentos forçado para cobertura de gastos que não estavam previstos.

Para a correta execução das tarefas inerentes ao planejamento tributário, o contador na função de gestor tributário precisa aplicar todos os seus conhecimentos sobre a legislação do tributo a ser reduzido, para que, a partir desses cenários, possa planejar com bastante antecedência a melhor alternativa para a empresa executar suas operações comerciais.

A finalidade principal de um bom planejamento tributário é, sem dúvida, a economia de impostos, sem infringir a legislação. Trata-se do conceito de tax saving ${ }^{13}$, bastante praticado pelos norte-americanos.
\end{abstract}

${ }^{13}$ Tax saving - Poupança Fiscal. 
Observa-se que as condições essenciais e adequadas para um bom planejamento estratégico tributário perpassam por uma gama de conhecimentos e técnicas que são adquiridas ao longo de vários anos de dedicação aos estudos das legislações tributárias por um profissional contador, o profissional dessa área precisa ser antes de tudo um gestor tributário para aplicar seus conhecimentos de forma direta e sagaz no atendimento a empresa, e levando em consideração toda a legislação vigente e existente, buscado de maneira primordial a economia de impostos sem infringir nenhuma lei.

\section{Planejamento estratégico tributário preventivo}

Oliveira; Chieregato; Júnior e Gomes (2011, p. 21), explanam que “num planejamento tributário estratégico, a empresa passa a desenvolver suas atividades de forma estritamente preventiva”. Entende-se que a prevenção no planejamento estratégico e a alma do negócio, pois antecipa possíveis perdas, possibilitando ganhos futuros. A objetividade fundamental no planejamento estratégico tributário será sempre a economia tributaria de impostos, atendendo sempre as legislações fiscais, dentro dos princípios da licitude, também conhecido como elisão fiscal e jamais o planejamento estratégico tributário procederá na ilicitude, que por sua vez se configura como evasão fiscal.

\section{Evasão fiscal, sonegação fiscal e elisão fiscal}

$\mathrm{Na}$ busca por um planejamento estratégico tributário eficaz, não se pode deixar de falar sobre evasão fiscal, sonegação fiscal e elisão fiscal, pois é preciso conhecer os significados destes termos para verificar como funciona a redução no recolhimento de impostos no Brasil. Dentro dos princípios da ilicitude, segundo o Cosife ${ }^{14}$ (2011):

${ }^{14}$ COSIFE - Confederação Nacional do Sistema Financeiro. 
incidência do tributo devido, não se configurando em hipótese alguma com o planejamento tributário lícito."

Tal ato configura-se como crime e está tipificado na Lei ${ }^{\circ} 8.137 / 90$, dos crimes contra a ordem tributária, econômica e contra as relações de consumo. Dessa forma os criminosos buscam reduzir a incidência tributável, através da fraude, falsificação, elaboração, distribuição, fornecimento, emissão, utilização e divulgação de instrumentos ilícitos, que promovem prejuízos para os negócios, para o governo e, consequentemente, para a sociedade. Lincoln (2011) explica que a sonegação fiscal "representa o ato de dissimular ou omitir, de forma total ou parcial, o pagamento do tributo". Apesar da evasão fiscal ser crime, cabe ressaltar também que a Lei n 9.249/95 dispôs em seu art. 34, que:

\begin{abstract}
Extingue-se a punibilidade dos crimes definidos na Lei $n^{\circ} 8.137$, de 27 de dezembro de 1990, e na Lei $n^{\circ} 4.729$. De 14 de julho de 1965, quando o agente promover o pagamento do tributo ou contribuição social, inclusive acessórios, antes do recebimento da denúncia.

A lei n ${ }^{\circ} 9.430 / 96$, determinou em seu artigo 83 , que a representação fiscal para fins penais, relativa aos crimes contra a ordem tributária, só será encaminhada ao Ministério Público após proferida a decisão final, na esfera administrativa, sobre a exigência fiscal do crédito tributário correspondente.
\end{abstract}

Dentro dos princípios da licitude, surge a terminologia elisão fiscal, que para o Cosife (2011) o termo “[...], representa a execução de procedimentos, antes do fato gerador, de forma legítima e ética, para reduzir, eliminar ou postergar a tipificação da obrigação tributária, caracterizando, assim, a legitimidade do planejamento tributário.” O objetivo da elisão fiscal é trazer economia, através da redução da carga tributária, através de um bom planejamento estratégico tributário, seguindo todas as leis existentes, ressalvando sempre que os valores devidos dos impostos devem ser sempre pagos.

\title{
Regimes de Tributação Existentes no Brasil
}

Os Regimes Tributários existentes no Brasil são quatro: Simples Nacional, Lucro Real, Lucro Presumido e Lucro arbitrado. O Simples nacional foi instituído e regulamentado pela Lei Complementar 123 de 2006. Já Lucro Real, Lucro Presumido e Lucro arbitrado são regulamentados pela legislação do Imposto de Renda (RIR), Decreto $\mathrm{n}^{\circ} 3.000$ de 26 de março de 1999 e suas respectivas leis complementares, que definem seus deveres e 
obrigações. Mas não iremos estudar nem analisar o último regime tributário (Lucro arbitrado), e sim apenas os três primeiros. É importantíssimo ressaltar que algumas empresas têm o direito de optar por um dos três regimes, outras são impedidas de utilizar algum destes regimes e outras obrigadas a utilizar determinado regime. A escolha do regime tributário que a empresa irá seguir poderá ser feita, a cada ano no mês de janeiro.

\section{Regime de Tributação: Simples Nacional}

O Simples Nacional, instituído e regulamentado pela Lei Complementar 123/2006, que instituiu, a partir de 01.07.2007, novo tratamento tributário simplificado. O Simples Nacional estabelece normas gerais relativas ao tratamento tributário diferenciado e favorecido a ser dispensado às microempresas e empresas de pequeno porte no âmbito da União, dos Estados, do Distrito Federal e dos Municípios, mediante regime único de arrecadação, inclusive obrigações acessórias. A lei complementar 123/06, estabelece a receita bruta que deve ser auferida em cada ano para que a empresa possa se enquadrar no Simples Nacional. Até 31/12/2017 em cada ano-calendário receita bruta não pode ultrapassara o limite de $\mathrm{R} \$$ 3.600.000,00 (três milhões e seiscentos mil reais). Entretanto, a partir de 01/01/2018 a lei complementar 155/16, publicada no Diário Oficial da União em 28/10/2016, passará a vigorar e modificará a lei 123/06, alterando as regras e limites, inclusive a forma de apuração do imposto.

No Simples nacional as empresas podem pagar vários impostos de uma só vez, através de um águia chamada de $\left(\mathrm{DAS}^{15}\right)$, esses impostos são descritos na Lei Complementar $\mathrm{n}^{\circ}$ 120/2006, art. 13, que são:

I - Imposto sobre a Renda da Pessoa Jurídica - IRPJ; II - Imposto sobre Produtos Industrializados - IPI, observado o disposto no inciso XII do $\S 1^{\circ}$ deste artigo; III Contribuição Social sobre o Lucro Líquido-CSLL; IV - Contribuição para o Financiamento da Seguridade Social - COFINS, observado o disposto no inciso XII do $\S 1^{\circ}$ deste artigo; V - Contribuição para o PIS/Pasep, observado o disposto no inciso XII do $\S 1^{\circ}$ deste artigo; VI - Contribuição Patronal Previdenciária - CPP para a Seguridade Social, a cargo da pessoa jurídica, de que trata o art. 22 da Lei ${ }^{\circ}$ 8.212, de 24 de julho de 1991, exceto no caso da microempresa e da empresa de pequeno porte que se dedique às atividades de prestação de serviços referidas no

${ }^{15}$ DAS - Documento de Arrecadação Simplificado. 
$\S 5^{\circ}$-C do art. 18 desta Lei Complementar; VII - Imposto sobre Operações Relativas à Circulação de Mercadorias e Sobre Prestações de Serviços de Transporte Interestadual e Intermunicipal e de Comunicação - ICMS; VIII - Imposto sobre Serviços de Qualquer Natureza - ISS.

A legislação brasileira permite a utilização desse regime tributário denominado de Simples Nacional, por viabilizar o pagamento de vários impostos de forma unificada, cabe as empresas fazerem seu planejamento estratégico tributário e decidirem se o mesmo é viável ou não, para o atendimento de suas demandas tributárias, é importante verificar se sua atividade comercial está incluída na lista de permissão para o Simples Nacional. Apuração do imposto no Simples Nacional é feito mensalmente.

\section{Regime de Tributação: Lucro Real e Lucro Presumido}

O RIR (1999), art. 247, conceitua Lucro Real como o lucro líquido do período de apuração ajustado pelas adições, exclusões ou compensações prescritas ou autorizadas por este (Decreto-Lei $\mathrm{n}^{\mathrm{o}}$ 1.598, de 1977, art. 6º $)$. O RIR (1999), art. 246, diz que o regime tributário chamado de Lucro Real: É obrigatório para as pessoas jurídicas (Lei $\mathrm{n}^{\circ}$ 9.718, de 1998, art. 14):

I - cuja receita total, no ano-calendário anterior, seja superior ao limite de vinte e quatro milhões de reais, ou proporcional ao número de meses do período, quando inferior a doze meses; II - cujas atividades sejam de bancos comerciais, bancos de investimentos, bancos de desenvolvimento, caixas econômicas, sociedades de crédito, financiamento e investimento, sociedades de crédito imobiliário, sociedades corretoras de títulos, valores mobiliários e câmbio, distribuidoras de títulos e valores mobiliários, empresas de arrendamento mercantil, cooperativas de crédito, empresas de seguros privados e de capitalização e entidades de previdência privada aberta; III - que tiverem lucros, rendimentos ou ganhos de capital oriundos do exterior; IV que, autorizadas pela legislação tributária, usufruam de benefícios fiscais relativos à isenção ou redução do imposto; V - que, no decorrer do ano-calendário, tenham efetuado pagamento mensal pelo regime de estimativa, na forma do art. 222; VI que explorem as atividades de prestação cumulativa e contínua de serviços de assessoria creditícia, mercadológica, gestão de crédito, seleção e riscos, administração de contas a pagar e a receber, compras de direitos creditórios resultante de vendas mercantis a prazo ou de prestação de serviços (factoring); Parágrafo único. As pessoas jurídicas não enquadradas nos incisos deste artigo poderão apurar seus resultados tributáveis com base nas disposições deste Subtítulo.

A empresa que optar pelo regime tributário do Lucro Real deve saber que a mesma terá um limite de $\mathrm{R} \$ 24.000 .000,00$ (vinte quatro milhões de reais), para ser obrigada, além de 
atividades especificas, contudo, qualquer empresa poderá optar por tal regime tributário e a mesma não terá limite de faturamento a ser obedecido. Esse regime não é cumulativo em relação ao PIS e à COFINS, existindo a possibilidade de creditamento. Apuração do imposto no Lucro Real pode ser feito anualmente ou trimestralmente.

O RIR (1999), art. 516, informa que as pessoas jurídicas autorizadas a optar ao regime tributário chamado de Lucro Presumido são:

\begin{abstract}
As que possuem receita bruta total, no ano-calendário anterior, tenha sido igual ou inferior a vinte e quatro milhões de reais, ou a dois milhões de reais multiplicado pelo número de meses de atividade no ano-calendário anterior, quando inferior a doze meses, poderá optar pelo regime de tributação com base no lucro presumido (Lei no 9.718, de 1998, art. 13). § 1을 opção pela tributação com base no lucro presumido será definitiva em relação a todo o ano-calendário (Lei n ${ }^{\circ} 9.718$, de 1998, art. $\left.13, \S 1^{\circ}\right) . \S 2^{\circ}$ Relativamente aos limites estabelecidos neste artigo, a receita bruta auferida no ano anterior será considerada segundo o regime de competência ou caixa, observado o critério adotado pela pessoa jurídica, caso tenha, naquele ano, optado pela tributação com base no lucro presumido (Lei n ${ }^{\circ} 9.718$, de 1998, art. 13, $\left.\S 2^{\circ}\right)$. § 3 o A pessoa jurídica que não esteja obrigada à tributação pelo lucro real (art. 246), poderá optar pela tributação com base no lucro presumido.§ 4 A opção de que trata este artigo será manifestada com o pagamento da primeira ou única quota do imposto devido correspondente ao primeiro período de apuração de cada anocalendário (Lei $n^{\circ} 9.430$, de 1996, art. 26, \& $1^{\circ}$ ).
\end{abstract}

A empresa que optar pelo regime tributário do Lucro Presumido deve saber que a mesma terá um limite de faturamento de até 78.000.000,00 (setenta e oito milhões de reais), a ser obedecido, contudo, a empresa que não esteja obrigada a tributação pelo lucro real, poderá optar. Esse regime é cumulativo em relação ao PIS e à COFINS, não existindo a possibilidade de creditamento. Apuração do imposto no Lucro Presumido é feito trimestralmente.

\title{
Alguns tributos existentes no Brasil
}

Segundo o Código Tributário Nacional - CTN, em seu art. 5\%, Os tributos são impostos, taxas e contribuições de melhoria. E para que se possa fazer um planejamento estratégico tributário eficiente é muito importante a familiarização por parte dos gestores tributários, com tais tributos, citaremos os mais relevantes abaixo:

IRPJ - imposto de renda da pessoa jurídica e a CSLL - contribuição social sobre o lucro líquido 
O CTN - Código Tributário Nacional, em seu art. 43 afirma que o imposto sobre a renda e proventos de qualquer natureza tem como fato gerador a aquisição da disponibilidade econômica ou jurídica. Assim, a alíquota aplicada é de $15 \%$ (quinze por cento) mais o adicional de $10 \%$ (dez por cento) sobre o excedente para as empresas optantes pelo Lucro Real, Presumido ou Arbitrado. Já a contribuição social sobre o lucro líquido CSLL, foi:

Instituída por meio da Lei $\mathrm{n}^{\circ} 7.689$, de 15 de dezembro de 1988 , cujo recolhimento é destinado ao financiamento da seguridade social. A alíquota atual da contribuição é de $15 \%$ (quinze por cento), no caso das pessoas jurídicas de seguros privados, das de capitalização e $9 \%$ (nove por cento), no caso das demais pessoas jurídicas. O art. 149 da Constituição Federal de 1988 autoriza a União a instituir contribuições sociais.

\section{PIS e o COFINS}

O PIS - Programa de Integração Social - foi instituído pela Lei Complementar $\mathrm{n}^{\circ}$ 7/1970, para financiar o seguro-desemprego e o abono anual de um salário mínimo aos trabalhadores que recebam até dois salários mínimos de remuneração mensal, nos termos do art. 239 da CF/1988. A COFINS - Contribuição para Financiamento da Seguridade Social - foi instituída pela Lei Complementar $n^{\text {o }}$ 70/1991, para custear as despesas da Previdência Social. A COFINS passou a ser exigida a partir de $1^{\circ}$ de abril de 1992, em substituição ao extinto FINSOCIAL.

CPP - contribuição patronal previdenciária e o ICMS - imposto sobre operações relativas à circulação de mercadorias e serviços

A Contribuição Patronal Previdenciária foi instituída pela Lei no 8.212, de 24 de julho de 1991, mais conhecida como Lei Orgânica da Seguridade Social. Esta lei é responsável pela regulamentação de toda a Seguridade Social Brasileira, sendo que as empresas, de um modo geral, são as principais fontes de financiamento desta. Todas as empresas, independentemente do Regime Tributário, estão obrigadas a recolher esta contribuição mensalmente. Já o Imposto Sobre Operações Relativas à Circulação de Mercadorias e sobre Prestações de Serviços de Transporte Interestadual e Intermunicipal e de Comunicações (ICMS) foi instituído pelo Decreto $n^{\circ} 6.284$ de 14 de março de 1997, e alterado pelo Decreto $n^{\circ} 13.780$ de 16 de março de 2012. Ele tem como fatos geradores: I - as operações relativas à circulação de mercadorias; II - prestações de serviços de transporte interestadual e intermunicipal; III - as prestações de serviços de comunicação. Este é um tributo de competência dos Estados, os quais são responsáveis pela elaboração de seu regulamento e pelo recolhimento do mesmo. 
É importante esclarecer que todos os impostos acima identificados, estão explicitados no Anexo 1, da tabela do Simples Nacional - comércio, com sua respectiva partilha. E tal tabela serviu de norte para a elaboração deste planejamento estratégico tributário.

\section{Método Adotado}

Para Gil (1999, p.42), a pesquisa é um "processo formal e sistemático de desenvolvimento do método cientifico. O objetivo fundamental da pesquisa é descobrir respostas para problemas mediante o emprego de procedimentos científicos". Quanto aos objetivos, a pesquisa a que se baseia este estudo é de natureza exploratória e descritiva. Para Beuren (2004, p. 81), "a pesquisa descritiva configura-se como estudo intermediário entre a pesquisa exploratória e a explicativa, ou seja, não é tão preliminar como a primeira, nem tão aprofundada como a segunda".

Quanto aos procedimentos, a pesquisa se apresenta como como um estudo de caso. Triviños (1987, p.113) afirma ser o estudo de caso "uma categoria de pesquisa cujo objeto é uma unidade que se analisa profundamente. "Ou seja, o estudo de caso está ligado a pesquisas que tenham um tema delimitado, para que o mesmo possa ser analisado de forma profunda.

Desse modo, a pesquisa se caracterizou como bibliográfica, pois abordou e explicou um determinado tema a partir de alguns referenciais. De acordo Cervo e Bervian (1983, p.55), pesquisa bibliográfica é a pesquisa que: "explica um problema a partir de referenciais teóricos publicados em documentos. Pode ser realizada independentemente ou como parte da pesquisa descritiva [...]". Assim neste projeto foi introduzida uma ação metodológica através do levantamento de cunho bibliográfico em Leis, Decretos, Protocolos, Artigos, Projetos, Livros e Textos on-line.

Quanto à abordagem, a natureza da pesquisa classifica-se como quantitativa. "Nas pesquisas documentais de cunho quantitativo, sobretudo naquelas que utilizam processamento eletrônico, os dados são organizados em tabelas e permitem o teste das hipóteses estatísticas". (GIL, 2002, p.90). Os resultados da pesquisa serão apresentados por meio de gráficos, com o auxílio do programa Microsoft Excel 2013, para tabulação e apresentação dos dados. 


\section{Analise e Discussão dos Resultados}

O objetivo geral da pesquisa consistiu-se em Avaliar a importância do planejamento estratégico tributário como ferramenta de gestão eficaz em uma empresa comercial do ramo varejista no recôncavo da Bahia. Que possuía no ano calendário de 2016, o regime tributário do Simples Nacional, contudo, se fez necessário o planejamento estratégico tributário para verificação de sua rentabilidade e competitividade em seu ramo de atividade, evitando dessa forma um possível desembolso, desnecessário, no pagamento de impostos no ano de 2017. Para que o planejamento estratégico tributário fosse feito de forma coerente e assertivo, a empresa simulou valores de vendas e compras, aqui informados, com o intuito de detectar o melhor regime tributário a ser utilizado a partir do ano calendário 2017. As vendas neste período foram de $\mathrm{R} \$ 1.176 .772,25$ (um milhão cento e setenta e seis mil setecentos e setenta e dois reais e vinte cinco centavos), já suas compras no mesmo período foram de $\mathrm{R} \$ 1.067 .217,47$ (um milhão e sessenta e sete mil duzentos e dezessete reais e quarenta e sete centavos).

Gráfico 1 - Regime Tributário: Simples Nacional.

\section{Simples Nacional}

$60.283,50$

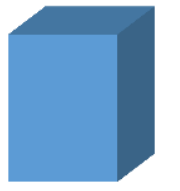

$$
1.848,00
$$

- Impostos Sobre as Vendas $37.566,05$

- Impostos Sobre a Folha de Pagamento

- Impotos Sobre as Compras

Fonte: Dados do Planejamento Estratégico Tributário/2017.

No gráfico 1, pode-se ver o primeiro regime tributário a ser analisado, que foi o Simples Nacional, pois, o mesmo, foi adotado pela empresa em todo ano-calendário de 2016.

As vendas efetuadas pela empresa, referentes ao ano calendário de 2017 , no período de janeiro a dezembro, foi de $\mathrm{R} \$ 1.176 .772,25$ (um milhão cento e setenta e seis mil 
setecentos e setenta e dois reais e vinte cinco centavos), porém para efeito de cálculo do imposto durante o período de janeiro a dezembro, foi considerado o valor acumulado das vendas que foi de $\mathrm{R} \$ 881.007,80$ (oito centos e oitenta e um mil sete reais e oitenta centavos), que depois de aplicadas as alíquotas do Simples Nacional, conforme a tabela do anexo 1 comércio, sobre o valor das vendas efetivas, encontrou-se o valor total a recolher de $\mathrm{R} \$$ $60.283,50$ (sessenta mil duzentos e oitenta e três reais e cinquenta centavos). Houve Retirada de pró-labore de janeiro a dezembro, de um sócio, perfazendo um total de 16.800,00 (dezesseis mil e oito centos reais), que foram multiplicados por uma alíquota de $11 \%$ e deu um total a recolher de $\mathrm{R} \$ 1.848,00$ (mil oitocentos e quarenta e oito reais). As compras efetuadas fora do estado deram um total de $\mathrm{R} \$ 426.886,99$ (quatro centos e vinte e seis mil oito centos e oitenta e seis reais e noventa e nove centavos), sobre uma alíquota de $7 \%$, como essas mercadorias são enquadradas como tributadas pelo RICMS-BA, o cálculo é feito segundo o diferencial de alíquota, ou seja, alíquota do estado da Bahia, menos a alíquota interestadual que nesse caso é de $7 \%$, então a diferença é de $11 \%$, com direito a redução de $20 \%$, para recolhimento até a data estipulada pelo governo estadual, o que deu um total de $\mathrm{R} \$$ 37.566,05 (trinta e sete mil quinhentos e sessenta e seis reais e cinco centavos).

Gráfico 2 - Regime Tributário: Lucro Real.

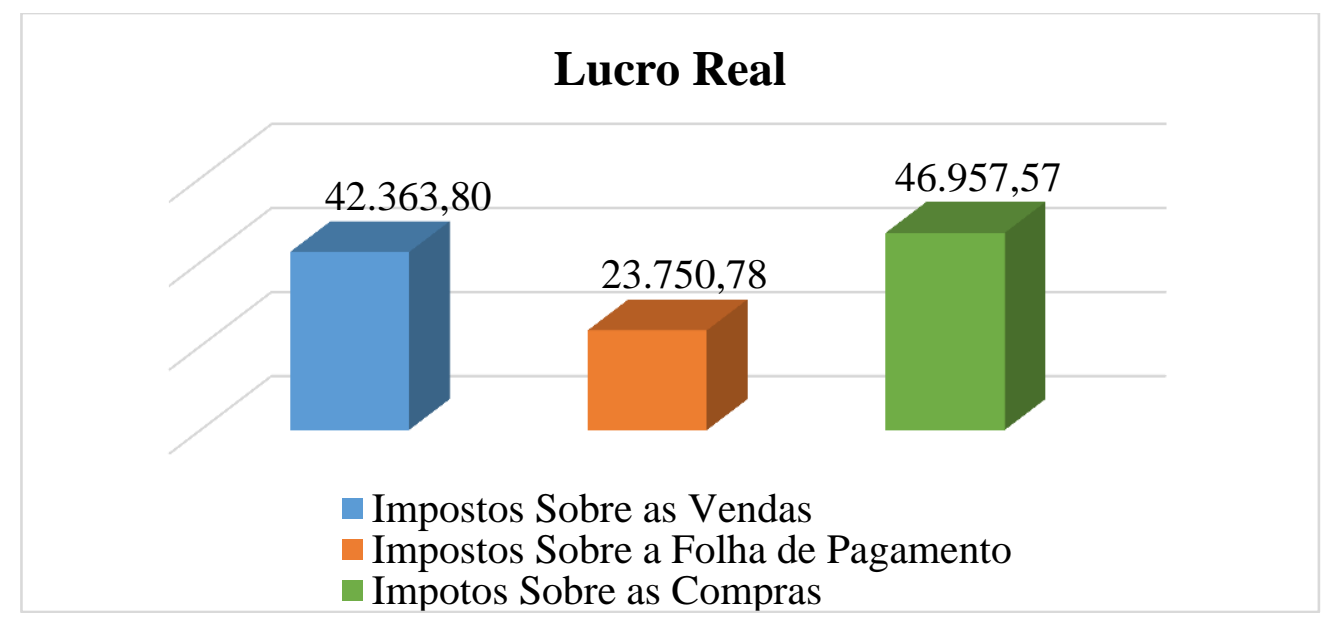

Fonte: Dados do Planejamento Estratégico Tributário/2017.

No gráfico 2, verificou-se o segundo regime tributário a ser analisado, que foi o Lucro Real, para efeito de comparação com os demais. Onde após feita a apuração do resultado do exercício de janeiro a dezembro, constatou-se um lucro de $\mathrm{R} \$ 176.515,84$ (cento 
e setenta e seis mil quinhentos e quinze reais e oitenta e quatro centavos), desse lucro foram apurados os seguintes impostos: IRPJ, alíquota de 15\%, CSLL, alíquota de 9\%, que deram um total a recolher de $\mathrm{R} \$ 42.363,80$ (quarenta e dois mil trezentos e sessenta e três reais e oitenta centavos). No lucro real a apuração do imposto pode ser feito anualmente ou trimestralmente. Esse regime é não cumulativo em relação ao PIS e à COFINS, existindo a possibilidade de creditamento, as alíquotas respectivamente são: PIS 1,65\% e COFINS 7,6\%, após as mesmas terem sido aplicadas sobre o valor das vendas de janeiro a dezembro, que foi de $\mathrm{R} \$$ 1.176.772,25 (um milhão cento e setenta e seis mil setecentos e setenta e dois reais e vinte cinco centavos), contatou-se um valor de PIS de R $\$ 19.416,74$ (dezenove mil quatro centos e dezesseis reais e setenta e quatro centavos), e de COFINS R \$ 89.434,69 (oitenta e nove mil quatro centos e trinta e quatro reais e setenta e nove centavos), que pode ser compensado com créditos de PIS e COFINS, sobre as entradas (compras), no valor de R $\$$ 98.717,62 (noventa e oito mil, setecentos e dezessete reais e sessenta e dois centavos). Houve Retirada de prólabore $(31 \%)$ e juntamente com o valor da folha de pagamento $(20 \%)$ de janeiro a dezembro, obteve-se um custo de $\mathrm{R} \$ 23.750,78$ (vinte e três mil, setecentos e cinquenta reais e setenta e oito centavos). As compras efetuadas fora do estado deram um total de $\mathrm{R} \$ 426.886,99$ (quatrocentos e vinte e seis mil oitocentos e oitenta e seis reais e noventa e nove centavos), multiplicado por uma alíquota interna (estado da Bahia), de 18\%, menos o crédito sobre a alíquota (interestadual) de 7\%, o que deu um total a recolher de $\mathrm{R} \$ 46.957,57$ (quarenta e seis mil novecentos e cinquenta e sete reais e cinquenta e sete centavos).

Gráfico 3 - Regime Tributário: Lucro Presumido.

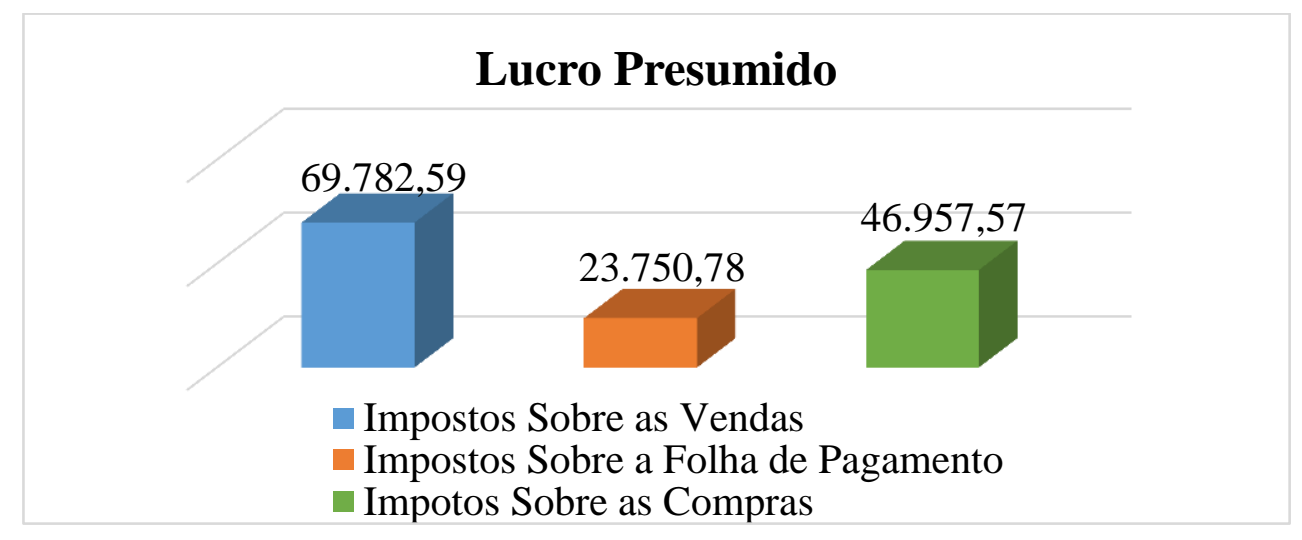

Fonte: Dados do Planejamento Estratégico Tributário/2017. 
No gráfico 3, pode-se ver o terceiro regime tributário a ser analisado, que foi o Lucro Presumido, para efeito de comparação com os demais. Onde o valor mensal das vendas de janeiro a dezembro, foi de $\mathrm{R} \$ 1.176 .772,25$ (um milhão cento e setenta e seis mil setecentos e setenta e dois reais e vinte cinco centavos), e após cálculo, contatou-se um valor de PIS de R\$ 7.649,02 (sete mil seiscentos e quarenta e nove reais e dois centavos), apurados sobre uma alíquota de $0,65 \%$ e COFINS de $\mathrm{R} \$ 35.303,17$ (trinta e cinco mil trezentos e três reais e dezessete centavos), apurados sobre uma alíquota de 3\%. Esse débito de imposto não pode ser compensado com créditos de PIS e COFINS, sobre as entradas (compras), pois, esse regime tributário é cumulativo em relação ao PIS e à COFINS. Também foram apurados, $15 \%$ de IRPJ incidente sobre um lucro pré-definido de $8 \%$ sobre o valor das vendas, para a maior parte do comércio, que perfez um valor total a recolher de $\mathrm{R} \$ 14.121,27$ (quatorze mil cento e vinte e um reais e vinte sete centavos), e $9 \%$ de CSLL, que incidiu sobre $12 \%$ da receita do comércio, que perfez um valor total a recolher de $\mathrm{R} \$ 12.709,14$ (doze mil setecentos e nove reais e quatorze centavos). Houve Retirada de pró-labore (31\%) e juntamente com o valor da folha de pagamento (20\%) de janeiro a dezembro, obteve-se um custo de $\mathrm{R} \$ 23.750,78$ (vinte e três mil, setecentos e cinquenta reais e setenta e oito centavos). As compras efetuadas fora do estado deram um total de $\mathrm{R} \$ 426.886,99$ (quatrocentos e vinte e seis mil oitocentos e oitenta e seis reais e noventa e nove centavos), multiplicado por uma alíquota interna (estado da Bahia), de $18 \%$, menos o crédito sobre a alíquota (interestadual) de $7 \%$, o que deu um total a recolher de $\mathrm{R} \$ 46.957,57$ (quarenta e seis mil novecentos e cinquenta e sete reais e cinquenta e sete centavos).

Gráfico 4 - Comparativo dos três Regimes Tributários analisados.

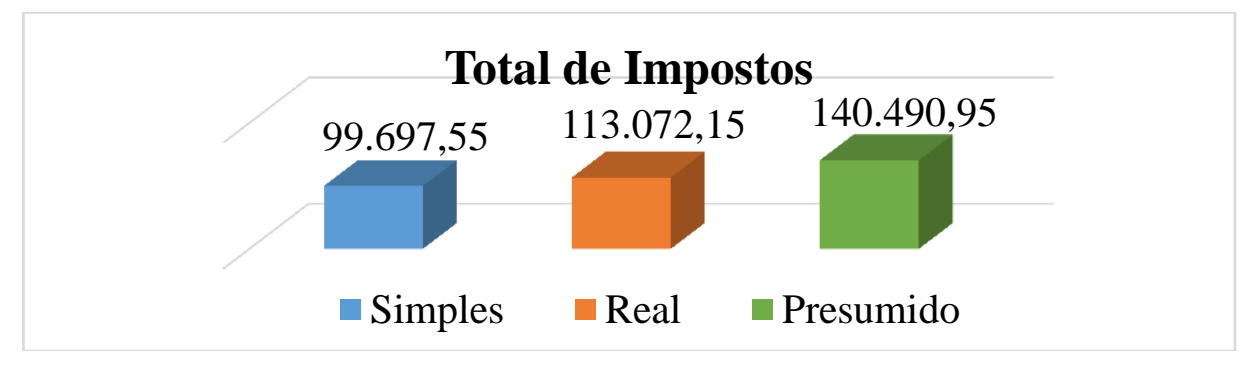

Fonte: Dados do Planejamento Estratégico Tributário/2017. 
No gráfico 4, pode-se ver o comparativo em valores de impostos dos três Regimes Tributários analisados, onde o valor total do imposto que deverá ser recolhido no regime tributário do Simples Nacional no período de doze meses será de $\mathbf{R} \mathbf{9 9 . 6 9 7 , 5 5}$ (noventa e nove mil seiscentos e noventa e sete reais e cinquenta e cinco centavos). E o valor total do imposto que deverá ser recolhido no regime tributário do Lucro Real será de R\$ 113.072,15 (cento e treze mil setenta e dois reais e quinze centavos). E por fim o valor total do imposto que deverá ser recolhido no regime tributário do Lucro Presumido será de R\$ 140.490,95 (cento e quarenta mil quatrocentos e noventa reais e noventa e cinco centavos). Dessa forma fica claramente evidenciado depois do planejamento estratégico tributário concluído, que o melhor regime tributário a ser adotado pela empresa no ano-calendário de 2017, será o do Simples Nacional, pois, o mesmo se mostrou tributariamente menos oneroso do que o Lucro Real ou o Lucro Presumido, diante dos valores de impostos simulados sobre as vendas, folha de pagamento e suas compras.

\section{Considerações Finais}

Com o objetivo de avaliar a importância do planejamento estratégico tributário como ferramenta de gestão eficaz em uma empresa comercial do ramo varejista no recôncavo da Bahia, foi preciso antes de tudo identificar o que seria planejamento estratégico tributário, e tal fato se revelou como sendo algo amplo e maximizado que possibilita à tomada de decisões dentro das empresas com foco principal na redução da carga fiscal/tributária, de maneira legal.

Por conseguinte, precisou-se analisar qual a importância do planejamento estratégico tributário dentro de uma empresa, sendo assim, foi constatado que o mesmo quando feito de forma lícita, causa uma diminuição legal no valor monetário (dinheiro), a ser repassado para o governo.

Fez se necessário também investigar a estrutura adequada para um bom planejamento estratégico tributário, o que trouxe a revelação de que a estrutura adequada para tal finalidade perpassa primordialmente por um arcabouço de conhecimentos e técnicas adquiridos através 
da dedicação ao estudo das leis tributárias por um profissional, com formação acadêmica ou não, que possa e saiba aplicar esses conhecimentos dentro da empresa, buscados de maneira primordial a economia de impostos, sem infringir as leis.

Houve também a necessidade de conhecimento acerca dos regimes de tributação existentes no Brasil, onde constatou-se que existem quatro regimes tributários, que são o Simples Nacional, o Lucro Real, o Lucro Presumido e o Lucro arbitrado. O Simples nacional foi instituído e regulamentado pela Lei Complementar 123 de 2006 e suas alterações, os outros três regimes são regulamentados pela legislação do Imposto de Renda (RIR), Decreto $\mathrm{n}^{\mathrm{o}} 3.000$ de 1999 e suas respectivas leis complementares, que definem seus deveres e obrigações.

Foi também necessário a detecção do melhor regime tributário a ser utilizado pela empresa alvo deste estudo, o que após a aplicação do planejamento estratégico tributário, identificou-se o Simples Nacional como tributariamente, o regime menos oneroso para o anocalendário de 2017.

O planejamento estratégico tributário mostrou-se uma excelente ferramenta de gestão eficaz para as empresas, pois, o mesmo serve para reduzir os custos referentes as finanças e tributos, através da definição do melhor regime tributário a ser adotado, além de prevenir eventuais erros nos lançamentos dos eventos tributários, diminuindo autuações fiscais e aumentando a competitividade através da redução dos custos, pois, a empresa terá mais recursos disponíveis para novos investimentos.

Contudo, para realizar o planejamento estratégico tributário, faz-se necessário a consulta a especialistas (Contadores, Administradores ou Advogados) que estudem e/ou trabalhem nas áreas de finanças e tributos, a fim de orientar a alta administração na projeção futura e preventiva para tomada de decisões de forma segura.

Assim o presente estudo não pretende ser conclusivo, porém sugere para trabalhos futuros uma pesquisa sobre a formação profissional interna dos colaboradores contábeis como ferramenta de maximização de resultados, já que tais profissionais (contadores ou não) são muitas vezes os responsáveis pela elaboração do planejamento estratégico tributário dentro ou fora das empresas. 


\section{Referências}

BAHIA. ICMS. Dec. $n^{\circ} 6.284$ de 14/97, alt. pelo Dec. no 13.780 de 16/03/12. Disponível em:http://mbusca.sefaz.ba.gov.br/DITRI/normas_complementares/decretos/decreto_2012_13 780_ricms texto.pdf. Acessado em 27/02/2017.

BEUREN, Ilse Maria. Como elaborar trabalhos monográficos em Contabilidade: teoria e prática. $2^{\circ}$ ed. São Paulo: Atlas, 2004.

BRASIL: Decreto $n^{0}$ 3.000, de 26/03/99, (RIR). Lei $n^{0}$ 9.249/95, alt. do (RIR). Disponível em:http://www.planalto.gov.br/ccivil_03/decreto/d3000.htm.http://www.planalto.gov.br/ccivil _03/leis/L9249.htm Acesso em: 24/02/2017.

BRASIL. Lei no 5.172, de 25/10/96 - Código Tributário Nacional - CTN.

BRASIL: Lei Complementar 120 de 2006. Disponível em:http://www.planalto.gov.br/ccivil_03/leis/LCP/Lcp120.htm. Acesso em: 24/02/2017.

BRASIL: Lei Complementar 123 de 2006 e Lei Complementar 155 de 2016. Disponível em:http://www.planalto.gov.br/ccivil_03/leis/LCP/Lcp123.htm.http://www2.camara.leg.br/leg in/fed/leicom/2016/leicomplementar-155-27-outubro-2016-783850-publicacaooriginal151329-pl.html. Acesso em: 24/02/2017.

BRASIL: Lei 6.404/76, Dispõe sobre as Sociedades por Ações. Disponível em: http://www.planalto.gov.br/ccivil_03/leis/L6404compilada.htm. Acesso em: 24/02/2017.

BRASIL: Lei 8.137/90, Define crimes contra a ordem tributária, econômica e contra as relações de consumo. Disponível em:http://www.planalto.gov.br/ccivil_03/leis/L8137.htm. Acesso em: 24/02/2017.

CATELLI, Armando. Contadoria uma Abordagem da Gestão Econômica-GECON. São Paulo: Atlas, 1999.

CERVO, Amado Luiz; BERVIAN, Pedro Alcino. Metodologia científica: para uso dos estudantes universitários. São Paulo: McGraw-Hill do Brasil, 1983.

COSIFE. O Contador diante do Planejamento Tributário e da Lei Antielisiva. Disponível em:http://www.cosif.com.br/publica.asp?arquivo=20040619elisao. Acesso em: 25/02/2017.

GIL. Antônio Carlos. Métodos e Técnicas de Pesquisa Social. 5º ed. São Paulo: Atlas, 1999. p.42.

GUBERT, Pablo Andrez Pinheiro. Planejamento Tributário: análise jurídica e ética. $2^{\circ}$ ed. Curitiba: Juruá, 2004. 
Id on Line Revista Multidisciplinar e de Psicoloqia

Id on Line Multidisciplinary and Psycology Journal

IBPT - Instituto Brasileiro de Planejamento Tributário. Disponível em: https://www.ibpt.com.br/. Acessado em 11/03/2017.

LINCOLN, João. Aspectos da Evasão, da Sonegação e da Elisão Fiscal. Disponível1em:1http://www.4shared.com/document/mAhdf_PV/3ASPECTOS_DA_EVASO _FISCAL_DA_S.htm. Acesso em: 26/02/2017.

MAXIMIANO, Antônio Cesar Amaru. Introdução à Administração. $6^{\circ}$ ed. São Paulo: Atlas, 2006.

OLIVEIRA, Luís Martins de. Contadoria Conceitos e Aplicações. São Paulo: Futura, 1998.

OLIVEIRA, Luís Martins de; CHIEREGATO, Renato; JÚNIOR, José Hernandez Perez; e GOMES, Marliete Bezerra. Manual de Contabilidade Tributária. $10^{\circ}$ ed. São Paulo: Atlas, 2011.

REVISTA EXAME.COM. Brasil tem maior carga tributária da América Latina. Rio de Janeiro. Disponível em:http://exame.abril.com.br/economia/brasil-tem-maior-carga-tributariada-america-latina/. Acesso em: 23/02/2017.

REVISTA O PROGRESSO. Brasil tem a $14^{\mathrm{a}}$ maior carga tributária do mundo. Mato Grosso do Sul, Dourados. Disponível em:http://www.progresso.com.br/caderno-a/economia/brasiltem-a-14-maior-carga-tributaria-do-mundo. Acesso em: 23/02/2017.

SEBRAE: Sobrevivência das Empresas no Brasil. Brasília. Disponível em:http://www.sebrae.com.br/Sebrae/Portal\%20Sebrae/Anexos/sobrevivencia-das-empresasno-brasil-relatorio-2016.pdf. Acesso em: 24/02/2017.

TRIVIÑOS, Augusto Nibaldo Silva. Introdução à pesquisa em ciências sociais: a pesquisa qualitativa em educação. São Paulo: Atlas, 1987.

Como citar este artigo (Formato ABNT):

FONSECA, Ubaldo de J.; VALE JÚNIOR,João S. do; ANDRADE, Magno D. G. de. Planejamento Estratégico Tributário: Um Estudo de Caso em Empresa do Ramo Varejista. Id on Line Revista Multidisciplinar e de Psicologia, 2017, vol.11, n.37, p. 360-379. ISSN: 1981-1179.

Recebido: 30.08.2017

Aceito: 01.09 .2017 